\title{
Enhanced Electrical Conductivities of N-doped Carbon Nanotubes by Controlled Heat Treatments
}

\author{
Kazunori Fujisawa, ${ }^{a}$ Tomohiro Tojo, ${ }^{a}$ Hiroyuki Muramatsu, ${ }^{b}$ Ana L. Elías, ${ }^{d}$ Sofía M. Vega-Díaz, ${ }^{c}$ \\ Ferdinando Tristán-López, ${ }^{c}$ Jin Hee Kim, ${ }^{a}$ Takuya Hayashi, ${ }^{a}$ Yoong Ahm Kim, ${ }^{a} *$ Morinobu Endo, ${ }^{a, b, c}$ and \\ ${ }_{5}$ Mauricio Terrones ${ }^{c, d}$
}

\author{
Received (in $X X X, X X X)$ Xth $X X X X X X X X X 20 X X$, Accepted Xth $X X X X X X X X X 20 X X$ \\ DOI: $10.1039 / b 000000 x$
}

The thermal stability of nitrogen $(\mathrm{N})$ functionalities on the sidewalls of $\mathrm{N}$-doped multi-walled carbon nanotubes was investigated at temperatures ranging between $1000{ }^{\circ} \mathrm{C}$ and $2000{ }^{\circ} \mathrm{C}$. The structural

10 stability of the doped tubes was then correlated to the electrical conductivity both at the bulk and at the individual tube levels. When as-grown tubes were thermally treated at $1000{ }^{\circ} \mathrm{C}$, we observed a very significant decrease in the electrical resistance of the individual nanotubes, from $54 \mathrm{k} \Omega$ to $0.5 \mathrm{k} \Omega$, which is attributed to a low $\mathrm{N}$ doping level (e.g. 0.78 at $\% \mathrm{~N}$ ). We noted that pyridine-type $\mathrm{N}$ was first decomposed whereas the substitutional $\mathrm{N}$ was stable up to $1500{ }^{\circ} \mathrm{C}$. For nanotubes heat treated to $1800{ }^{\circ} \mathrm{C}$ 15 and $2000{ }^{\circ} \mathrm{C}$, the tubes exhibited an improved degree of crystallinity which was confirmed by both the low R value $\left(I_{D} / I_{G}\right)$ in the Raman spectra, and the presence of straight graphitic planes observed in TEM images. However, $\mathrm{N}$ atoms were not detected in these tubes and caused an increase in their electrical resistivity and resistance. These partially annealed doped tubes with enhanced electrical conductivities could be used in the fabrication of robust and electrically conducting composites, and these results could

20 be extrapolated to $\mathrm{N}$-doped graphene and other nanocarbons.

\section{Introduction}

The modification of the electronic and optical properties of carbon nanotubes via the introduction of nitrogen atoms into the nanotube sidewalls has been explored. ${ }^{1-3} \mathrm{~N}$ atoms have been 25 incorporated into carbon nanotubes by the thermal decomposition of $\mathrm{N}$ containing compounds or vapor over metal nanoparticles at high temperatures. ${ }^{4-17}$ The $\mathrm{N}$-doped carbon nanotubes have showed metallic behavior, characterized by the presence of a donor state close to the Fermi level. ${ }^{18-23}$ In addition, they may 30 have potential applications as efficient supporting materials for anchoring catalytic particles ${ }^{24-26}$; as catalysts for the oxygen reduction reaction in fuel cells ${ }^{27-30}$; as high-performance electron field emitters ${ }^{20,31-33}$; as a highly selective electron transport materials for solar cell ${ }^{34}$; and as a multifunctional filler in 35 polymeric composites ${ }^{35-37}$. In addition, the incorporation of $\mathrm{N}$ atoms is known to improve the biocompatibility of carbon nanotubes ${ }^{38}$.

The unusual properties and potential applications of $\mathrm{N}$-doped carbon nanotubes can be explained by the way $\mathrm{N}$ atoms are ${ }_{40}$ bonded to $\mathrm{C}$ atoms on the sidewalls of nanotubes. It has been reported that the amount and type of $\mathrm{N}$ functionalities within $\mathrm{N}$ doped carbon nanotubes could be controlled by varying the synthetic conditions, such as the reaction temperature, the type of catalyst and the feedstock. ${ }^{39,40}$ Moreover, the electrical 45 conductivity of the bulk material is roughly proportional to the amount of $\mathrm{N}$ atoms incorporated in the structure. ${ }^{17,21,23}$ Four types of $\mathrm{N}$ atoms have been identified in carbon nanotubes by $\mathrm{X}$-ray photoelectron spectroscopy (XPS) studies: pyridinic, pyrrolic, quaternary and oxidized pyridinic $\mathrm{N}$. When considering the 50 potential applications of N-doped multi-walled carbon nanotubes, it is essential to understand the effect of the different $\mathrm{N}$ functionalities on the electrical conductivity of individual carbon nanotubes, in order to tailor the $\mathrm{N}$ functionalities and thus control the electrical transport of the nanotubes.

${ }_{55}$ In this paper, we report an approach able to tune both the content of $\mathrm{N}$ functionalities and the electrical conductivity via hightemperature thermal treatments. Specifically, as-grown N-doped multi-walled carbon nanotubes (N-MWNTs) were thermally treated at temperatures ranging between $1000{ }^{\circ} \mathrm{C}$ and $2000{ }^{\circ} \mathrm{C}$ in ${ }_{60}$ argon and the variation in their electrical conductivity, at both the bulk and the individual tube scale, were correlated to the thermal stability of $\mathrm{N}$ functionalities. The quaternary $\mathrm{N}$ atoms $(\mathrm{N}$ bonded to three carbon atoms) were thermally stable up to $1500{ }^{\circ} \mathrm{C}$. The individual nanotubes annealed at $1000{ }^{\circ} \mathrm{C}$ exhibited the lowest 65 electrical resistance, even lower to the values observed in highly crystalline nanotubes produced using an arc discharge.

\section{Experimental details}

The N-doped N-MWNTs were synthesized by the decomposition of a solution containing $2.5 \mathrm{wt} \%$ ferrocene and benzylamine $70(97.5 \mathrm{wt} \%)$, as previously described. ${ }^{41}$ The produced N-MWNTs 
were then heat treated under an argon flow for $30 \mathrm{~min}$ at various temperatures, ranging from $1000{ }^{\circ} \mathrm{C}$ to $2000{ }^{\circ} \mathrm{C}$, using a graphite furnace. Before heating, the graphite furnace was vacuumed $(0.13$ $\mathrm{MPa}$ ) and then flushed with argon gas $(1 \mathrm{~L} / \mathrm{min})$ in order to 5 eliminate oxygen or exclude the possibility of oxidation in nanotube sample. The morphology and texture of the pristine and heat-treated tubes were characterized using scanning electron microscopy (SEM, JEOL JSM-6335Fs) and high-resolution transmission electron microscopy (HRTEM, CEOS Double Cs 10 corrector equipped JEOL JEM-2100F, 120 kV). Raman spectra were collected using a T64000 Triple Raman Spectrometer (Horiba Jobin Yvon) with four different laser lines (488, 514, 633 and $785 \mathrm{~nm}$ ), and the curve fitting was carried out using the Lorentzian distribution function. The electrical resistivity of $\mathrm{N}$ 15 MWNTs in the bulk state was measured using the four-point probe method (Mitsubishi Chemical, PD-51). The electrical resistance of an individual carbon nanotube was measured by the following procedure: a nanotube suspension was spin-coated on $\mathrm{SiO}_{2}$ electrode, and the electrode patterns were formed by 20 depositing tungsten (W) on an individual carbon nanotube by focused-ion-beam lithography (SMI2059, SII, Japan), in order to exclude the contact resistance between the carbon nanotube and the electrode. The intrinsic resistance was obtained from the linear current-voltage relationship from -1 to $1 \mathrm{~V}$ (Advantest, TR25 6143).

\section{Results and discussion}

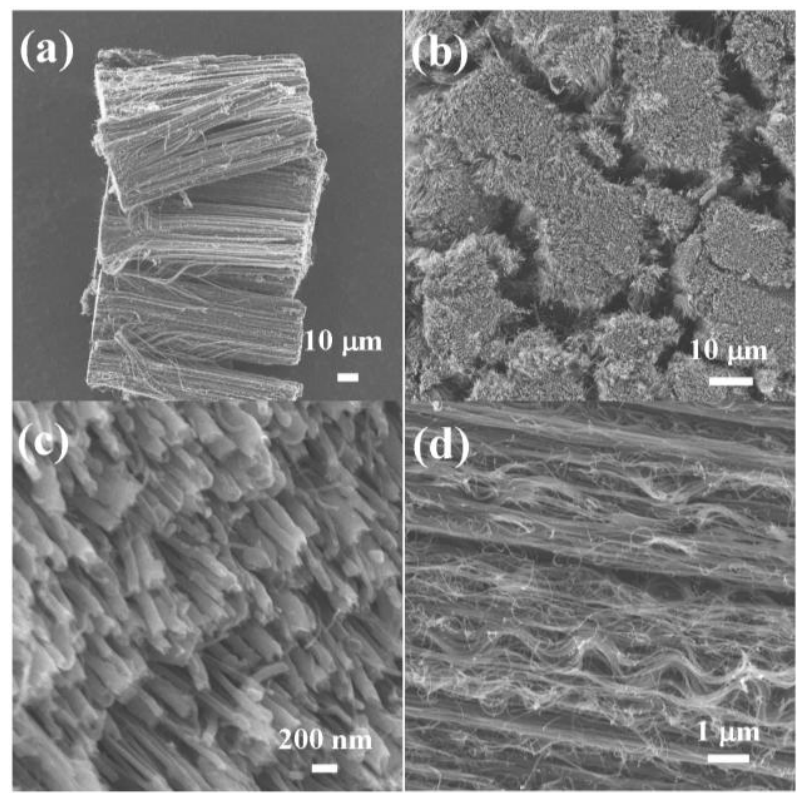

Fig. 1 (a-d) SEM images of vertically aligned N-doped MWNTs at different angles and magnifications. Note that the tube ends are opened.

As-grown N-doped carbon nanotubes consisted of large bundles 30 (Fig. $1(\mathrm{a}, \mathrm{b})$ ) of aligned nanotubes (Fig. 1 (d)). In some cases, the ends of the tubes were open (Fig. 1 (c)). High-temperature thermal treatment was employed to modify both the surface functionalities and the degree of crystallinity within the carbon nanotubes. This heat treatment appears to be a powerful tool for 35 improving their structural integrity, and could effectively remove trapped metallic impurities, particularly Fe below 20 ppm. ${ }^{42-44}$ In this particular study, as-grown N-MWNTs were thermally treated in argon at temperatures between $1000{ }^{\circ} \mathrm{C}$ and $2000{ }^{\circ} \mathrm{C}$, using a graphite furnace.
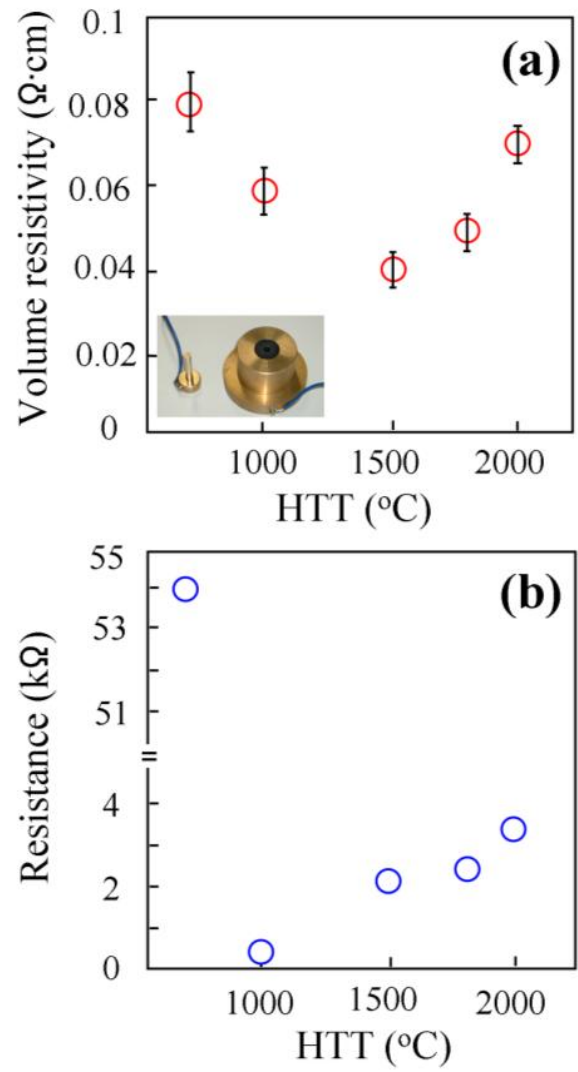

40 Fig. 2 (a) Variation in the volumetric resistivity of N-doped MWNTs as a function of heat treatment temperature at a density of $1.23 \mathrm{~g} / \mathrm{cm}^{3}$; the inset shows the sample holder. (b) Variation of the electrical resistance of an individual $\mathrm{N}$-doped MWNT as a function of heat treatment temperature.

In order to understand the structural and electrical transport 45 changes within our N-doped MWNTs, we measured the electrical resistivity in the bulk state using a four-point probe method (Fig. 2 (a)). A specific amount of the carbon nanotubes was placed in the sample holder (Fig. 2 (a), inset), and the resistivity at a nanotube mass density of $1.23 \mathrm{~g} / \mathrm{cm}^{3}$ was measured. In order to 50 study conductivity changes induced by the Fe encapsulates, we have conducted bulk conductivity measurements of hydrochloric acid $(\mathrm{HCl})$ treated N-doped MWNTs, and observed no significant change in the electrical resistance in bulk. Therefore, the Fe particles appear not to play a critical role in the electrical 55 transport of the "metal-free" N-doped MWNTs. For tubes heat treated at below $1500{ }^{\circ} \mathrm{C}$, a rapid decrease in electrical resistivity was observed, which can be explained by the removal of surface functional groups and aromatic hydrocarbons from the outer surface of the doped carbon nanotubes. However, for tubes heat 60 treated above $1500{ }^{\circ} \mathrm{C}$, a continuous increase in volumetric resistivity was detected. In addition, the electrical resistance of an individual tube was measured (Fig. 2 (b)). The intrinsic resistance of an individual tube was obtained from a linear current-voltage relationship up to $1 \mathrm{~V}$. The lowest electrical resistance $(0.5 \mathrm{k} \Omega)$ 65 was observed in the tubes heat treated at $1000{ }^{\circ} \mathrm{C}$, although tubes prepared at $2000{ }^{\circ} \mathrm{C}$ still exhibited a relatively low electrical 


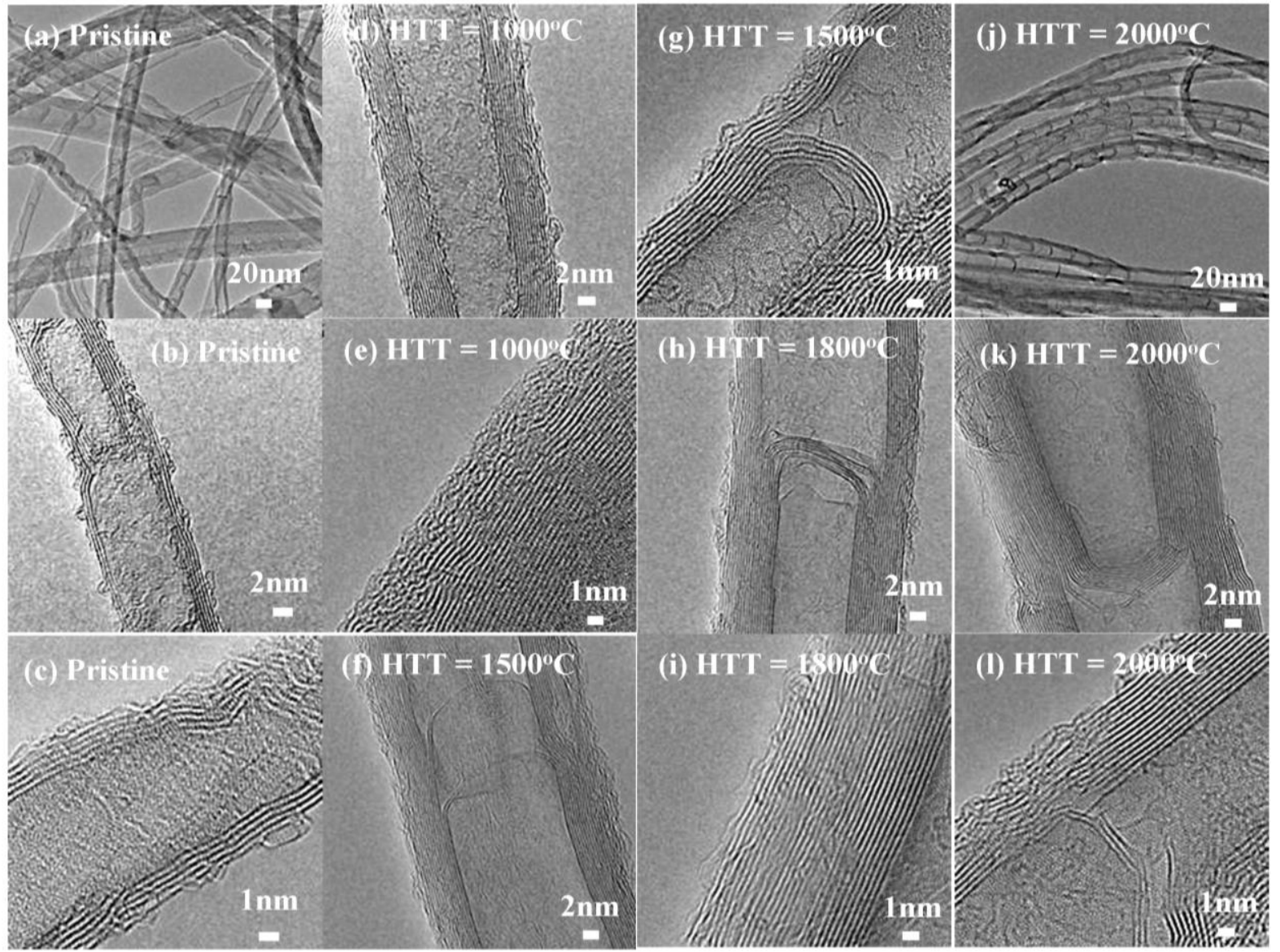

Fig. 3 HRTEM images of (a-c) pristine N-MWNTs and thermally annealed N-MWNTs, under an argon atmosphere, at (d, e) $1000^{\circ} \mathrm{C}$, (f, g) $1500{ }^{\circ} \mathrm{C}$, (h, i) $1800{ }^{\circ} \mathrm{C}$ and (j-1) $2000^{\circ} \mathrm{C}$.
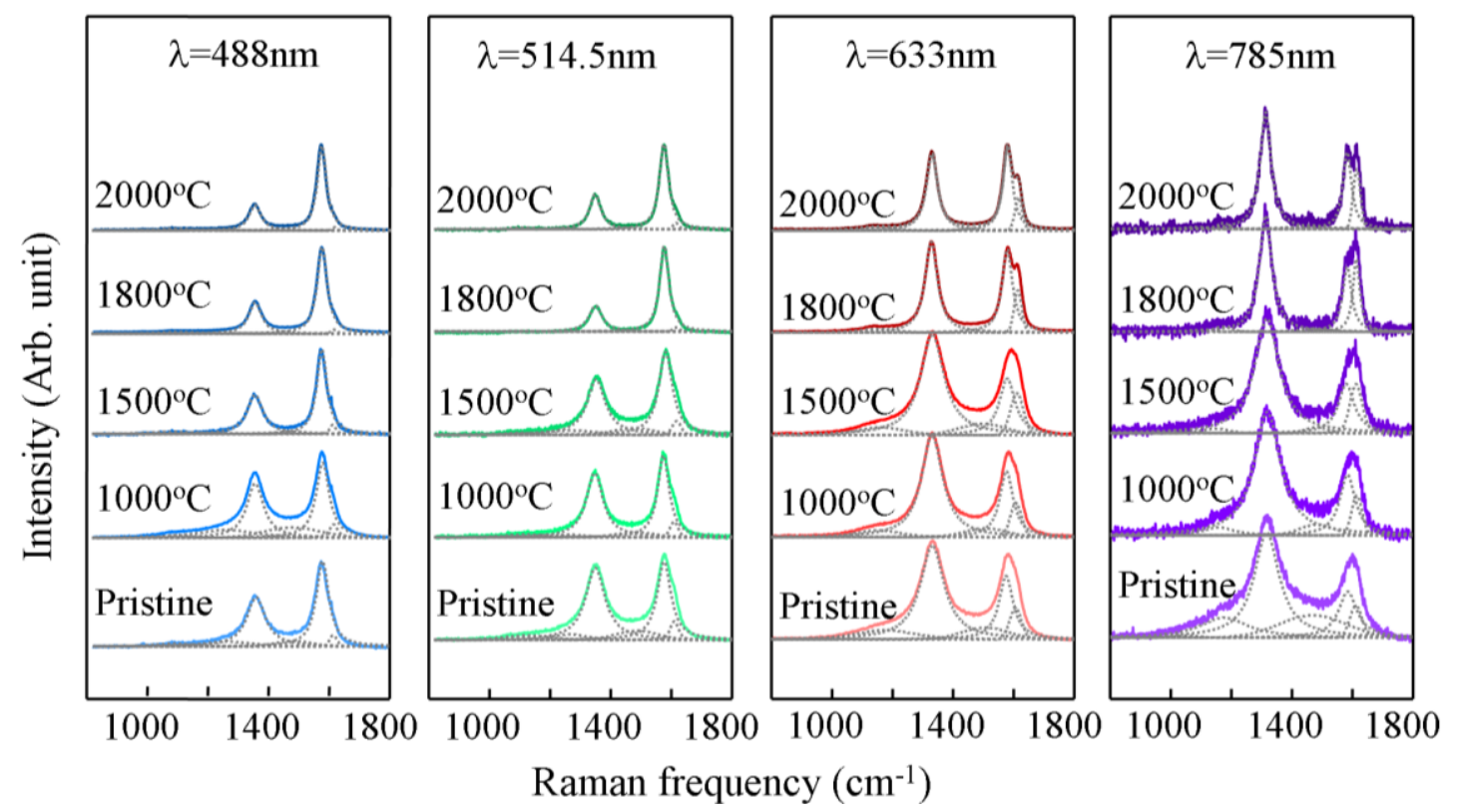

Fig. 4 Raman spectra of pristine N-doped MWNTs and thermally annealed N-doped MWNTs, in an argon atmosphere, at temperatures ranging between $1000{ }^{\circ} \mathrm{C}$ and $2000{ }^{\circ} \mathrm{C}$, using four laser lines $(488,514.5,633$ and $785 \mathrm{~nm})$.

resistance $(3.5 \mathrm{k} \Omega$ ). It is noteworthy that an arc-produced (pure carbon) MWNT has been reported to exhibit a resistance of 2.4 $\mathrm{k} \Omega$ at room temperature. ${ }^{45}$ Thus, the lowest electrical resistance value in our nanotubes arises from the partial content of $\mathrm{N}$ atoms 5 (doping), which is consistent with several reported papers. ${ }^{18-23}$ However, the increase in the electrical resistance of carbon 


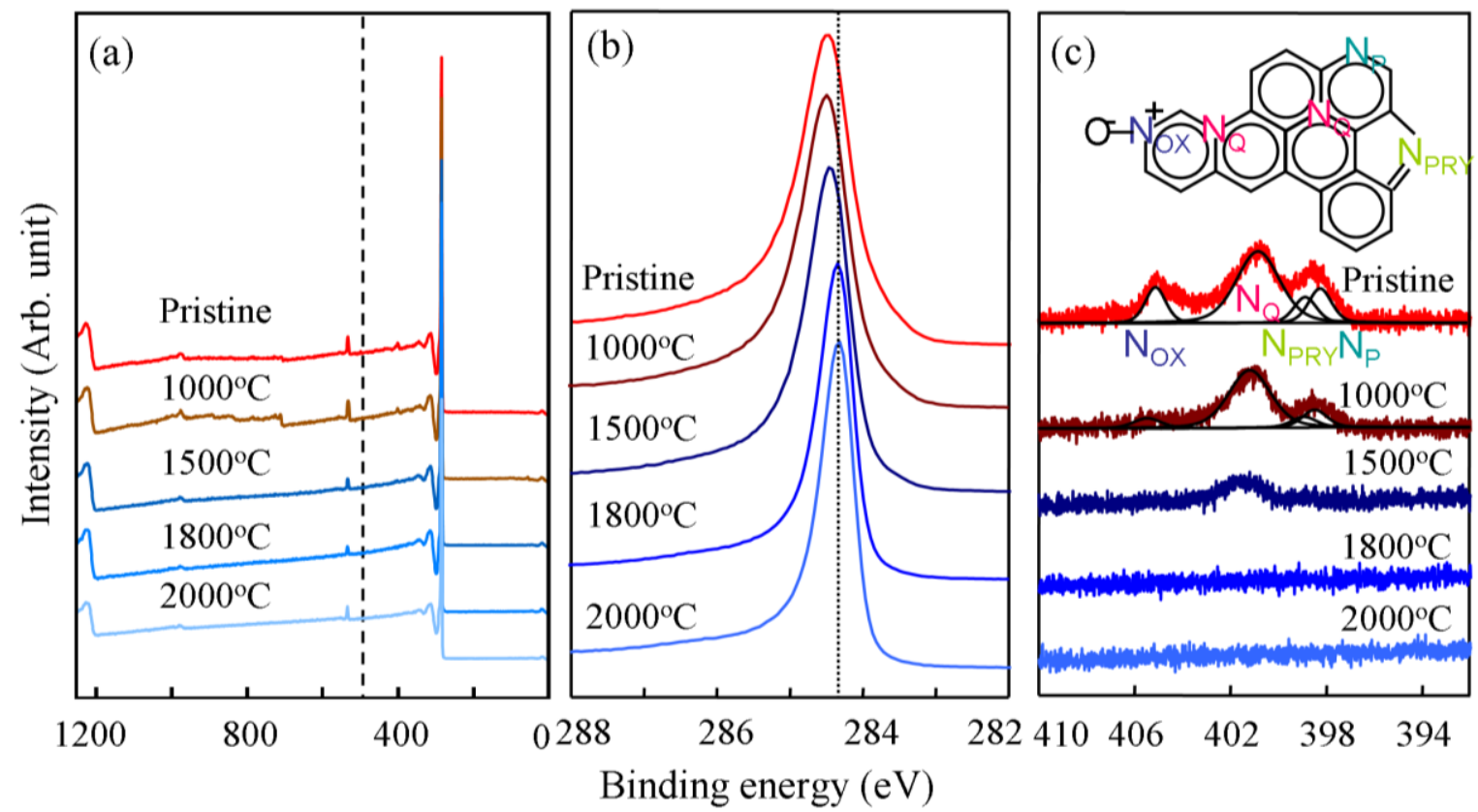

Fig. 5 XPS data of pristine N-doped MWNTs and thermally annealed N-doped MWNTs at temperatures ranging between $1000{ }^{\circ} \mathrm{C}$ and $2000{ }^{\circ} \mathrm{C}$. (a) The wide-scan, (b) $\mathrm{C}$ 1s region and (c) $\mathrm{N} 1$ s region.

nanotubes that are thermally treated at temperatures ranging between $1500{ }^{\circ} \mathrm{C}$ and $2000{ }^{\circ} \mathrm{C}$ is not usually observed for undoped carbon nanotubes (Fig. S1). This increase in electrical resistivity and resistance for tubes at temperatures between $51500{ }^{\circ} \mathrm{C}$ and $2000{ }^{\circ} \mathrm{C}$ may be attributed to the absence of $\mathrm{N}$ atoms within the nanotubes. There are two opposing effects caused by high temperature thermal treatment which affect the electrical conductivity of N-doped carbon nanotubes: one is the improved structural integrity of the carbon nanotubes (enhanced degree of 10 crystallinity), and the other is the change in concentrations and type of the $\mathrm{N}$ atoms incorporated within the hexagonal lattice of the tubes.

In order to obtain visual confirmation of the improved structural integrity, HR-TEM images of the pristine and the thermally 15 treated tubes were obtained (see Fig. 3). As-grown nanotubes were long, linear, and exhibited a bamboo-like structure with regularly arranged compartments contained in a hollow core (Fig. 3 (a)). In addition, the graphene layers of the as-produced tubes were corrugated, indicating a low degree of structural 20 crystallinity casued by the introduction of $\mathrm{N}$ atoms (Fig. 3 (b, c)). In this context, the introduction of $\mathrm{N}$ atoms into the graphitic layer is known to create pentagons which facilitate the formation of distorted or defective layers. ${ }^{40,46}$ We noted a distinctive change in the HRTEM images for nanotubes that were thermally treated 25 at $1000{ }^{\circ} \mathrm{C}$ and $1500{ }^{\circ} \mathrm{C}$ (Fig. $3(\mathrm{~d}-\mathrm{g})$ ). As the temperature was increased to $1800{ }^{\circ} \mathrm{C}$ and $2000{ }^{\circ} \mathrm{C}$, the short, corrugated fringes became long, straight layers (Fig. 3 (h-l)), thus indicating an improvement in the structural integrity caused by the thermal annealing. In addition, the internal caps were transformed from 30 round cap morphologies (Fig. 3 (g)) into more facetted caps (Fig. $3(\mathrm{k})$ ). This kind of morphological change is often seen at the tip of thermally treated nanotubes, ${ }^{42-44}$ because the facetted structure is energetically more stable at high temperatures.

Raman spectra on the different samples were recorded using four
35 laser lines (488, 514.5, 633 and $785 \mathrm{~nm}$ ) (Fig. 4), and this analysis provides quantitative information about the near-surface region of carbon nanotubes. ${ }^{47}$ There were two distinctive lines in the Raman spectra: the G-band $\left(E_{2 g 2}\right)$ located at $1580 \mathrm{~cm}^{-1}$, and the D-band (defect-induced mode) appearing at $1350 \mathrm{~cm}^{-1}$. As the 40 wavelength of the laser lines increased, the D-band became more intense and downshifted, in accordance with double resonance theory. ${ }^{48}$ For N-MWNTs that were thermally treated below $1500{ }^{\circ} \mathrm{C}$, there was no distinctive change in the Raman spectra. As the temperature increased from $1500{ }^{\circ} \mathrm{C}$ to $2000{ }^{\circ} \mathrm{C}$, the half 45 width at half maximum intensity of the G-band and the intensity of the D-band decreased, thus indicating that the defects were progressively removed upon thermal annealing.

The D'-band simultaneously appears in the Raman spectra of nanotubes thermally treated at $1800{ }^{\circ} \mathrm{C}$ and $2000{ }^{\circ} \mathrm{C}$ when using 50 laser lines of 633 and $785 \mathrm{~nm}$. In order to quantify the structural changes, the R value $\left(I_{D} / I_{G}\right.$, the integrated intensity of the $\mathrm{D}$ band divided by the integrated intensity of the $\mathrm{G}$ band) was plotted as a function of the heat treatment temperature (Fig. S2); the R value has been previously used as an indicator of the crystalline ${ }_{55}$ structure of carbon materials, including carbon nanotubes. ${ }^{49,50}$ For nanotubes heat treated at temperatures below $1500{ }^{\circ} \mathrm{C}$, the presence of defects and surface functional groups decrease and some $\mathrm{N}$ atoms remain embedded in the hexagonal framework of the tubes. However, for the tubes treated at $1800{ }^{\circ} \mathrm{C}$ and $2000{ }^{\circ} \mathrm{C}$, 60 the defects are completely annealed by the high temperatures, and the presence of $\mathrm{N}$ dopant disappears (see XPS data below).

Finally, the surface functionalities of the doped nanotubes, and their stability at high temperatures were examined using XPS. The wide-scan XPS spectra of the as-grown tubes revealed peaks 65 located at $284.4 \mathrm{eV}$ (C 1s), $400 \mathrm{eV}$ (N 1s) and $532.2 \mathrm{eV}$ (O 1s) (Fig. 5 (a)). However, after a thermal treatment at $1800{ }^{\circ} \mathrm{C}$, the intensity of the $\mathrm{O} 1 \mathrm{~s}$ peaks decreased by a factor of 2 , and the $\mathrm{N}$ 1s peak disappeared. In order to quantify these changes, the 
atomic concentrations of carbon $(\mathrm{C})$, oxygen $(\mathrm{O})$ and $\mathrm{N}$ atoms are summarized in Table 1.

A consecutive decrease in the content of foreign atoms is observed as a function of the heat treatment temperature. This 5 process increases the carbon content via the elimination of foreign atoms such as $\mathrm{N}, \mathrm{O}$ and iron $(\mathrm{Fe})$. The removal of $\mathrm{Fe}$ was observed in nanotubes treated at $1500{ }^{\circ} \mathrm{C}$, whereas the elimination of $\mathrm{N}$ atoms was noted in nanotubes treated at $1800^{\circ} \mathrm{C}$ The residual $\mathrm{O}$ content in nanotubes treated above $1500{ }^{\circ} \mathrm{C}$ is 10 probably arising from water physically adsorbed on the carbon materials or present in the XPS chamber. These changes were reflected in the $\mathrm{C} 1 \mathrm{~s}$ spectra (Fig. 5 (b)). As the temperature increased, the peaks changed in shape from asymmetric to symmetric, and the full width at half maximum substantially 15 decreased. Furthermore, the peaks were shifted to a lower binding energy, approching the energy of the $s p^{2} \mathrm{C}-\mathrm{C}$ bond of graphite. The $\mathrm{N}$ 1s spectra were magnified in order to identify the $\mathrm{N}$ functionalities, determine their thermal stability as a function of heat treatment temperature (Fig. 5 (c)). The $\mathrm{N} 1 \mathrm{~s}$ peak was 20 deconvoluted into four peaks: the peak located at $398.5 \mathrm{eV}$ corresponds to pyridine-like $\mathrm{N}$, the peak located at $400.1 \mathrm{eV}$ from the pyrrolic $\mathrm{N}$; the strong signal at $401.4 \mathrm{eV}$ originated from the quaternary graphite-like $\mathrm{N}$ or substitutional $\mathrm{N}$; and a weak peak located at 402-405 eV is assigned to an oxygenated $\mathrm{N}$ group. ${ }^{51,52}$

${ }_{25}$ When as-grown N-MWNTs (containing 2.7 at $\%$ of $\mathrm{N}$ ) were thermally treated at $1000{ }^{\circ} \mathrm{C}$, preferential evolution of the oxygenated $\mathrm{N}$ atoms was observed ( $\mathrm{N}$ content of 0.78 at \%; see Table 1), which resulted in a large decrease in the electrical resistance of the individual nanotubes from $54 \mathrm{k} \Omega$ to $0.5 \mathrm{k} \Omega$. The 30 majority of the pyridine-like $\mathrm{N}$ decomposed, whereas the quaternary $\mathrm{N}$ remained stable up to $1500{ }^{\circ} \mathrm{C}$. For N-MWNTs heat treated at $1800{ }^{\circ} \mathrm{C}$ and $2000{ }^{\circ} \mathrm{C}$, we could not identify $\mathrm{N}$ atoms. However, the detection limit of this XPS is $\sim 0.1$ atom $\%$. Therefore, the observed electrical resistance for tubes treated at $351800{ }^{\circ} \mathrm{C}$ and $2000{ }^{\circ} \mathrm{C}$, suggests that even a small number of $\mathrm{N}$ atoms below 0.1 atom \% could be present within the nanotubes. Studies using second-ion mass spectroscopy are in progress in order to detect the residual $\mathrm{N}$ atoms within tubes that are thermally treated at $1800{ }^{\circ} \mathrm{C}$ and $2000{ }^{\circ} \mathrm{C}$.

40 Table 1 Atomic composition of N-doped multi-walled carbon nanotubes thermally treated at various temperatures.

\begin{tabular}{|c|c|c|c|c|c|c|c|c|}
\hline \multirow{2}{*}{ I.D. } & \multicolumn{4}{|c|}{$\begin{array}{l}\text { Atomic composition } \\
(\text { atom \%) }\end{array}$} & \multicolumn{4}{|c|}{ Nitrogen functionality (\%) } \\
\hline & $\mathrm{C}$ & $\mathrm{O}$ & $\mathrm{N}$ & $\mathrm{Fe}$ & $\mathrm{N}_{O X}{ }^{\mathrm{a}}$ & $\mathrm{N}_{\mathrm{Q}}{ }^{\mathrm{b}}$ & $\mathrm{N}_{\mathrm{PYR}}{ }^{\mathrm{c}}$ & $\mathrm{N}_{\mathrm{P}}^{\mathrm{d}}$ \\
\hline Pristine & 89.4 & 7.7 & 2.7 & 0.17 & 13.3 & 62.1 & 9.2 & 15.4 \\
\hline $\mathrm{HTT}=1000^{\circ} \mathrm{C}$ & 90.1 & 8.8 & 0.78 & 0.35 & 6.0 & 72.8 & 8.2 & 13.0 \\
\hline $\mathrm{HTT}=1500^{\circ} \mathrm{C}$ & 96.1 & 3.6 & 0.32 & - & - & 100 & - & - \\
\hline $\mathrm{HTT}=1800^{\circ} \mathrm{C}$ & 96.7 & 3.3 & - & - & - & & - & - \\
\hline $\mathrm{HTT}=2000^{\circ} \mathrm{C}$ & 97.1 & 2.9 & - & - & - & & - & - \\
\hline
\end{tabular}

\section{${ }_{45}$ 4. Conclusions}

We have reported the temperature-dependent changes of the $\mathrm{N}$ functionalities and electrical conductivities of N-MWNTs that were thermally treated in argon at temperatures ranging between $1000{ }^{\circ} \mathrm{C}$ and $2000{ }^{\circ} \mathrm{C}$. When as-grown $\mathrm{N}$-doped nanotubes 50 (containing 2.7 at $\%$ of $\mathrm{N}$ ) were treated at $1000{ }^{\circ} \mathrm{C}$, a substantial decrease in the electrical resistance, from $54 \mathrm{k} \Omega$ to $0.5 \mathrm{k} \Omega$, was attributed to the removal of the oxygenated $\mathrm{N}$ atoms and surface groups ( $\mathrm{N}$ content of 0.78 at \%). At $1500{ }^{\circ} \mathrm{C}$, the pyridine-like $\mathrm{N}$ decomposed, whereas the quaternary $\mathrm{N}$ remained stable $(\mathrm{N}$

55 content of 0.32 at \%). Even though an enhanced degree of crystallinity was observed in N-MWNTs heat treated at $1800{ }^{\circ} \mathrm{C}$ and $2000{ }^{\circ} \mathrm{C}$, verified by both the low $\mathrm{R}$ value in the Raman spectra and the presence of straight graphitic domains, the absence of the $\mathrm{N}$ atoms within the sidewall of tubes gave rise to a 60 subtle increase in their electrical resistivity and resistance both at the bulk material and at the individual tube level. However, the low electrical resistance observed in individual tubes prepared at $1800{ }^{\circ} \mathrm{C}$ and $2000{ }^{\circ} \mathrm{C}$, suggested that a small number of $\mathrm{N}$ atoms (below 0.1 atom \%) could still be present within the nanotubes. ${ }_{65}$ Individual N-MWNTs heat treated at $1000{ }^{\circ} \mathrm{C}$ showed the lowest electrical resistance, caused by an an adequate concentration of pyridinic and quaternary $\mathrm{N}$ atoms, and could potentially be used as an effective supporting material for anchoring catalytic nanoparticles or as multifunctional fillers in polymeric 70 composites.

\section{Acknowledgements}

We acknowledge the support from the Regional Innovation Cluster Program of Nagano from the Ministry of Education, Culture, Sports, Science and Technology of Japan. JHK 75 acknowledges the support of Shinshu University Global COE Program "International Center of Excellence on Fiber Engineering”. MT, SMVD, FTL and ME acknowledge support from the Research Center for Exotic NanoCarbon Project, Japan regional Innovation Strategy Program by the Excellence, JST.

\section{${ }_{80}$ Notes and references}

${ }^{a}$ Faculty of Engineering, Shinshu University, 4-17-1 Wakasato, Nagano 380-8553, Japan. Fax: +81-26-269-5208; Tel: +81-26-269-5212; Email:yak@endomoribu.shinshu-u.ac.jp

${ }^{b}$ Carbon Institute of Science and Technology, Shinshu University, 4-17-1 85 Wakasato, Nagano 380-8553, Japan.

${ }^{c}$ Research Center for Exotic Nanocarbons (JST), Shinshu University, Wakasato 4-17-1, Nagano 380-8553, Japan.

${ }^{d}$ Department of Physics, Department of Materials Science and

Engineering \& Materials Research Institute, The Pennsylvania State 90 University, 104 Davey Lab., University Park, PA 16802-6300, USA

$\dagger$ Electronic Supplementary Information (ESI) available: [Variations of electrical resistivity of undoped carbon nanotubes that are thermally treated at temperatures of $1000-2000{ }^{\circ} \mathrm{C} \mathrm{C}$ in argon (Fig. S1), and Variations in the $R$ value of carbon nanotubes which are thermally treated 95 at 1000 and $2000{ }^{\circ} \mathrm{C}$ in $\operatorname{argon}$ (Fig. S2)]. See DOI: 10.1039/b000000x/

1 M. Terrones, A. Jorio, M. Endo, A. M. Rao, Y. A. Kim, T. Hayashi, H. Terrones, J.-C. Charlier, G. Dresselhaus, M. S. Dresselhaus, Materials Today, 2004, 7, 30-45.

2. M. Terrones, A. G. Souza Filho, A. M. Rao, In Carbon Nanotubes: 100 Advanced Topics in the Synthesis, Structure, Properties and Applications (Edited by A. Jorio, M. S. Dresselhaus, G. Dresselhaus), Springer, New York, 2008, 531-566.

3. P. Ayala, R. Arenal, M. Rummeli, A. Rubio, T. Pichler, Carbon, 2011, 48, 575-586. 
4. M. Terrones, A. M. Benito, C. Manteca-Diego, W. K. Hsu, O. I. Osman, J. P. Hare, D. G. Reid, H. Terrones, A. K. Cheetham, K. Prassides, H. W. Kroto, D. R. M. Walton, Chem. Phys. Lett., 1996, 257, 576-582.

5 5. T. Belz, A. Bauer, J. Find, M. Gunter, D. Herein, H. Mockel, N. Pfänder, H. Sauer, G. Schulz, J. Schütze, O. Timpe, U. Wild, R. Schlögi, Carbon, 1998, 36, 731-741.

6. K. Suenaga, M. P. Johansson, N. Hellgren, E. Broitman, L. R. Wallenberg, C. Colliex, J. -E. Sundgren, L. Hultman, Chem. Phys. Lett., 1999, 300, 695-700.

7. M. Terrones, P. Redlich, N. Grobert, S. Trasobares, W. K. Hsu, H. Terrones, Y.Q. Zhu, J.P. Hare, C.L. Reeves, A. K. Cheetham, M. Rühle, H.W. Kroto, D.R.M. Walton, Adv. Mater., 1999, 11, 655-658.

8. M. Terrones, N. Grobert, H. Terrones, Carbon, 2002, 40, 1665-1684.

159 . Y. T. Lee, N. S. Kim, J. Park, J. B. Han, Y. S. Choi, H. Ryu, H. J. Lee, Chem. Phys. Lett., 2003, 372, 853-859.

10. M. Glerup, M. Castignolles, M. Holzinger, G. Hug, A. Loiseau, P. Bernier, Chem. Commun., 2003, 2542-2543.

11. C. P. Ewels, M. Glerup, J. Nanosci. Nanotechnol., 2005, 5, 13451363.

12. A. G. Kudashov, A. V. Okotrub, L. G. Bulusheva, I. P. Asanov, Y. V. Shubin, N. F. Yudanov, L. I. Yudanova, V. S. Danilovich, O. G. Abrosimov. J. Phys. Chem. B, 2004, 108, 9048-9053.

13. C. Tang, Y. Bando, D. Goldberg, F. Xu, Carbon, 2004, 42, 26252633.

14. H. C. Choi, J. Park, B. Kim, J. Phys. Chem. B, 2005, 109, 4333-4340.

15. S. Y. Kim, J. Lee, C. W. Na, J. Park, K. Seo, B. Kim, Chem. Phys. Lett., 2005, 413, 300-305.

16. S. van Dommele, K.P. de Jong, J. H. Bitter, Chem. Commun., 2006, 4859-4861.

17. D. H. Lee, W. J. Lee, S. O. Kim, Nano Lett., 2009, 9, 1427-1432.

18. D. Tekleab, R. Czerw, D. L. Carroll, P. M. Ajayan, Appl. Phys. Lett., 2000, 76, 3594-3596.

19. R. Czerw, M. Terrones, J. C. Charlier, X. Blase, B. Foley, R.

35 Kamalakaran, N. Grobert, H. Terrones, D. Tekleab, P. M. Ajayan, W. Blau, M. Ruehle, D. L. Carrol, Nano Lett., 2001, 1, 457-460.

20. D. Golberg, P. S. Dorozhkin, Y. Bando, Z. C. Dong, C. C. Tang, Y. Uemura, N. Grobert, M. Reyes-Reyes, H. Terrones, M. Terrones, Appl. Phys. A-Mater., 2003, 76, 499-507.

40 21. F. Villapando-Paez, A. Zamudio, A. L. Elias, H. Son, E. B. Barros, S. G. Chou, Y. A. Kim, H. Muramatsu, T. Hayashi, J. Kong, H. Terrones, G. Dresselhaus, M. Endo, M. Terrones, M. S. Dresselhaus, Chem. Phys. Lett., 2006, 424, 345-352.

22. W. J. Zhang, J. Y. Zhang, P. J. Li, X. Shen, Q. F. Zhang, J. L. Wu, $45 \quad$ Nanotechnology, 2008, 19, 085202.

23. J. D. Wiggins-Camacho, K. J. Stevenson, Effect of Nitrogen Concentration on Capacitance, J. Phys. Chem. C, 2009, 113, 1908219090.

24. K. Jiang, L. S. Schadler, R. W. Siegel, X. J. Zhang, H. F. Zhang, M. Terrones, J. Mater. Chem., 2004, 14, 37-39.

25. K. Jiang, A. Eitan, L. S. Schadler, P. M. Ajayan, R. W. Siegel, N. Grobert, M. Mayne, M. Reyes-Reyes, H. Terrones, M. Terrones, Nano Lett., 2003, 3, 275-277.

26. A. Zamudio, A. L. Elias, J. A. Rodriguez-Manzo, F. Lopez-Urias, G.

55 Rodriguez-Gattorno, F. Lupo, M. Ruhle, D. J. Smith, H. Terrones, D. Diaz, M. Terrones, Small, 2005, 2, 346-350.

27. P. H. Matter, E. Wang, J. M. Millet, U. S. Ozkan, J. Phys. Chem. C, 2007, 111, 1444-1450.

28. S. Maldonado, K. J. Stevenson, J. Phys. Chem. B, 2005, 109, 47074716.

29. S. Kundu, T. C. Nagaiah, W. Xia, Y. Wang, S. van Dommele, J. H. Bitter, M. Santa, G. Grundmeier, M. Bron, W. Schuhmann, M. Muhler, J. Phys. Chem. C, 2009, 113, 14302-14310.

30. K. Gong, F. Du, Z. Xia, M. Durstock, L. Dai, Science, 2009, 323, 760-764.

31. M. Doytcheva, M. Kaiser, M. Reyes-Reyes, M. Terrones, N. de Jonge, Chem. Phys. Lett., 2004, 396, 126-130.

32. D. H. Lee, J. A. Lee, W. J. Lee, S. O. Kim, Small 2011, 7, 95-100.

33. D. H. Lee, J. E. Kim, T. H. Han, J. W. Hwang, S. J. S.-Y. Choi, S. H.

70 Hong, W. J. Lee, R. S. Ruoff, S. O. Kim, Adv. Mater. 2010, 22, $1247-1252$.
34. J. M. Lee, J. S. Park, S. H. Lee, H. Kim, S. Yoo, S. O. Kim, $A d v$. Mater. 2011, 23, 629-633.

35. B. Fragneaud, K. Masenelli-Varlot, A. Gonzalez-Montiel, M. 75 Terrones, J. Y. Cavaille, Chem. Phys. Lett., 2005, 419, 567-573.

36. M. Dehonor, K. Masenelli-Varlot, A. Gonzalez-Montiel, C. Gauthier, J. Y. Cavaille, H. Terrones, M. Terrones, Chem. Commun., 2005, 5349-5351.

37. B. Fragneaud, K. Masenelli-Varlot, A. Gonzalez-Montiel, M. Terrones, J. Y. Cavaille, Chem. Phys. Lett., 2007, 444, 1-8.

38. J. L. Carrero-Sanchez, A. L. Elias, R. Mancilla, G. Arellin, H. Terrones, J. P. Laclette, M. Terrones, Nano Lett., 2006, 6, 1609-1616.

39. S. van Dommele, A. Romero-Izqirdo, R. Brydson, K. P. de Jong, J. H. Bitter, Carbon, 2008, 46, 138-148.

85 40. B. G. Sumpter, V. Meunier, J. M. Rome-Herrera, E. Cruz-Silva, D. A. Cullen, H. Terrones, D. J. Smith, M. Terrones, ACS Nano, 2007, 1, 369-375.

41. M. Terrones, P. M. Ajayan, F. Banhart, X. Blase, D. L. Carroll, J. C. Charlier, R. Czerw, B. Foley, N. Grobert, R. Kamalakaran, P. Kohler-

90 Redlich, M. Rühle, T. Seeger, H. Terrones, Appl. Phys. A, 2002, 74, 355-361.

42. Y. A. Kim, K. Osada, T. Hayashi, M. Endo, M. S. Dresselhaus, Chem. Phys. Lett., 2003, 380, 319-324.

43. Y. A. Kim, T. Hayashi, M. Endo, Y. Kaburagi, T. Tsukada, J. Shan, K. Osato, S. Tsuruoka, Carbon, 2005, 43, 2243-2250.

44. J. Chen, A. Kuno, M. Matsuo, T. Tsukada, T. Tamura, K. Osato, J. Y. Shan, F. Munekane, Y. A. Kim, T. Hayashi, M. Endo, Carbon, 2008 , 46, 391-396.

45. B. Q. Wei, R. Vajtai, P. M. Ajayan, Appl. Phys. Lett., 2001, 79, 1172-1174

46. H. Sjostrom, S. Stafstrom, M. Boman, J. E. Sundgren, Phys. Rev. Lett., 1995, 75, 1336-1339.

47. M. S. Dresselhaus, G. Dresselhaus, R. Saito, A. Jorio, Phys. Rep., 2005, 409, 47-99.

105 48. R. Saito, A. Gruneis, G. G. Samsonideze, V. W. Brar, G. Dresselhaus, M. S. Dresselhaus, A. Jorio, L. G. Cancado, C. Fantini, M. A. Pimenta, A. G. Souza-Filho, New. J. Phys., 2003, 5, 157.

49. L. G. Cancado, K. Takai, T. Enoki, M. Endo, Y. A. Kim, H. Mizusaki, L. N. Coelho, R. Magalhaes Paniago, A. Jorio, and M. A. Pimenta, Appl. Phys. Lett., 2006, 88, 163106.

50. M. A. Pimenta, G. Dresselhaus, M. S. Dresselhaus, L. G. Cançado, A. Jorio and R. Saito, Phys. Chem. Chem. Phys., 2007, 9, 1276-1290.

51. E. Raymundo-Pinero, D. Cazorla-Amoros, A. Linares-Solano, J. Find, U. Wild, R. Schlogl, Carbon, 2002, 40, 597-608.

115 52. J. R. Pels, F. Kapteijin, J. A. Moulijn, Q. Zhu, K. M. Thomas, Carbon, 1995, 33, 1641-1653. 